A detailed description of the ODTS has been produced with an application form, guidelines for training scheme organisers and for overseas sponsors. There is also an open letter to potential trainees in psychiatry overseas.

\section{Regional Meetings of the Royal College of Psychiatrists}

The Council of the Royal College of Psychiatrists has approved guidelines for holding overseas meetings, entitled 'Regional Meetings for Members and Fellows of the Royal College of Psychiatrists Overseas'. The first such meeting took place in Cairo from 10-12 March 1989. There is a provisional intimation of a Regional Meeting of the College to take place in Pakistan, possibly in 1990. Further Regional Meetings are under discussion.

The initiative for such meetings should come from a Member overseas with good local links in psychiatry. Such a local convenor will undertake the administrative arrangements with assistance and advice from the College. These meetings are intended primarily for Members and Fellows of the College in the host and neighbouring countries. Probably such Regional Meetings will take place alongside nonCollege psychiatric meetings but the College programme should be kept separate. One or more of the College Officers will be invited to the Regional Meetings, and the programme will be reviewed by the Programmes and Meetings Committee of the College.

In North America there has been for some time a 'chapter' of the Royal College of Psychiatrists. This comprises all Members and Fellows in North America. There have been occasional meetings of this group, taking place, for example, at the same time as meetings of the American Psychiatric Association.

\section{Mutual recognition}

The Overseas Desk has been making further enquiries of the details for mutual recognition in Europe. At the recent meeting of the College with the Department of Health enquiries were made concerning the implications of 1992 for postgraduate psychiatric training and exchange with Europe. The work of the Union Europenne des Médecins Spécialistes and particularly of its Monospecialist Committee in Psychiatry has been explored. Professor Sims and Dr Caldicott recently visited the German Society for Psychiatry and Nervous Diseases and discussed medical education and postgraduate training in psychiatry in the Federal Republic of Germany.

Contact has been made and there has been correspondence with the relevant postgraduate psychiatric organisations in Canada, Australia, New Zealand and the USA.

The Overseas Desk has established a list of experts, based in the UK, for different parts of the world, who will be able to give us information to facilitate smooth operation of the Overseas Doctors' Training Scheme and other matters of concern. Overseas Members and Fellows have been informed by letter of the work of the Overseas Desk.

Comments and suggestions, requests for further information, and offers of expert advice would be welcome at the Overseas Desk. We wish to receive applications for the Overseas Doctors Training Scheme both from those in training in psychiatry overseas and from organisers of training schemes in the United Kingdom. For further information at the Royal College of Psychiatrists contact Suzanna Goodwyn, Assistant Education Officer.

Professor A. C. P. Sims

\title{
London hotels
}

Members have requested information about hotel accommodation near the College. Within the immediate area, most hotels are either excessively expensive or of poor quality. However, members may apply to the Finance Officer for the names of two hotels providing adequate accommodation at a reasonable price, and details of the BMA's London Hotels Priority Registration Services.

I would also be glad to receive members' comments on the suggested hotels and/or recommendations for alternatives.

W. D. Boyd Treasurer

\section{Election to the Fellowship 1990}

The following Member was elected a Fellow of the College by the Court of Electors:

Professor Jiang Zuo Ning. 